\title{
Las políticas de Pedro I con respecto a la comunidad Sefardí y la Sinagoga del Tránsito como testimonio político material
} The policies of Peter I regarding the Sephardic community
and the Synagogue of Transit as material political testimony

Pablo Gumiel Campos

Departamento de Historia y Teoría del Arte, Universidad Autónoma de Madrid

RESUMEN: El rey Pedro I de Castilla, impulsado por sus ambiciones políticas y económicas de carácter autoritario, fue un gran benefactor de la comunidad sefardí. Este pro semitismo sin embargo fue utilizado por su hermanastro Enrique de Trastámara como un arma propagandística durante la Primera Guerra Civil Castellana. Con el fin de ganar adeptos el conde Enrique incendió las conciencias sociales populares contra el pueblo judío, llegando a protagonizar varios ataques armados en las juderías castellanas. La Sinagoga del Tránsito de Toledo se nos presenta como un testimonio material de estos acontecimientos cargado de connotación e intencionalidad política.

PALABRAS ClAVE: Pedro I, Enrique II, Sinagoga del Tránsito, Comunidad sefardí, Toledo.

\begin{abstract}
King Peter I of Castile, moved by his authoritarian politics and economic ambitions, became a huge benefactor of the Sephardi community. However, this pro-Jewish attitude was used by Henry of Trastámara as a fail-safe propaganda weapon during the First Castilian Civil War. In order to win people over to his cause, count Henry influenced the public consciousness against the Jews; he even attacked some Castilian Jewries. Tránsito Synagogue of Toledo it is a material testimony of these events and a building full of political connotations and purpose.
\end{abstract}

KEYWORDS: Peter I, Henry II, Tránsito Synagogue, Sephardi Community, Toledo 
Para muchos autores el siglo XIV representa el punto de arranque del antisemitismo en la sociedad castellana y la ruptura de la armonía judeocristiana (Valdeón, 2000a, p. 49). En efecto, en Castilla, desde comienzos del reinado de Alfonso XI (1331-1350) encontramos una serie de recortes en las libertades de la comunidad hebrea. En el año 1339, dos escándalos financieros envolvieron a la comunidad judía complicando la atmosfera. Se dijo que un judío de la corte, Samuel ibn Wakkar, había recomendado al rey, como una emergencia de guerra, suspender todas las relaciones comerciales con Granada, causando con ello una crisis hacendística en el reino. En consecuencia Alfonso XI, instigado por Gonzalo Martínez, Maestre de Alcántara, procedió a confiscar cuantiosos vienes a los judíos (Suarez, 1980, p. 174). Además a raíz de las campañas militares alfonsíes la presión fisscal fue en aumento y de la mano fueron incrementándose las acusaciones a los judíos. Poco a poco en las distintas cortes se fueron proponiendo y aprobando una serie de medidas antisemitas. La última de ellas, previa al reinado de Pedro I de Castilla se fijó solamente dos años antes de la muerte del rey Don Alfonso a manos de la peste en el sitio de Gibraltar. En las Cortes de Alcalá de Henares de 1348, se estableció la prohibición a los judíos de prestar dinero con intereses (Valdeón, 2000a, p. 55).

Bajo el reinado de Pedro I (1350-1369) encontramos sin embargo un cambio drástico de tendencia. Como afirma Julio Valdeón, "hubo, pese a todo, una etapa de relativa bonanza para los judíos de Castilla, la que se corresponde, "grosso modo", con la década que va de 1350 a 1360, y que coincide buena parte con el reinado de Pedro I" (Valdeón, 2000a, p. 57). El filo semitismo de Pedro I de Castilla tenía una explicación de carácter político-económico. El rey castellano tenía como ambición fundamental el fortalecimiento de la monarquía sobre la nobleza y el clero. Pedro I tenía en mente la elaboración de un proyecto (Rucquo, 1987, p. 10) que reafirmara el poder de la monarquía, encaminándola hacia un nuevo modelo de institución (Ladero, 1991, p. 484). Bajo su gobierno, la monarquía castellana adquirió un sentido fuertemente personalista, una concepción del poder inspirada sin duda en el ejemplo de los gobiernos despóticos orientales (Valdeón, 1966, p.71), y más en concreto en la tradición política andalusí. En este contexto político, el pueblo sefardí, representaba para el rey don Pedro la base económica sobre la que cimentar su ideología, y por ello siempre protegió sus intereses.

\section{Las medidas político-sociales de Pedro I en favor al pueblo judío}

La protección de los intereses de la comunidad sefardí se vio reflejada en primer lugar en una serie de medidas políticas de carácter social en la que el rey se mostró propenso a proteger los intereses hebreos. La primera de estas medidas fue la anulación, durante las cortes de Valladolid de 1351, de lo acordado 
por su padre en las cortes de 1348, es decir el rey abolió la prohibición a los judíos de prestar dinero con intereses. Con esta medida, el joven don Pedro dejó claras sus intenciones actuando en favor de los intereses semitas (Valdeón, 2000a, p. 58).

Encontramos otro ejemplo en una provisión real enviada el 2 diciembre de 13531 dirigida a las justicias de Toledo, en la cual, el rey don Pedro ejerce su potestad mediando en un conflicto en defensa de la Aljama. Los procuradores de la ciudad de Toledo acusaban a los judíos de retener como esclavos a los musulmanes conversos, y demandaban la liberación de los mismos. El monarca, decide convocar a un procurador de la ciudad, y un representante de la Aljama de los judíos para esclarecer toda la verdad (Díaz Martín, 1997, p. 202). Años más tarde, el 27 de mayo de 1367, ya en plena guerra civil, Pedro I envía una carta al concejo de la ciudad de Cartagena2, ordenando que se paguen todas las deudas que se deben a los judíos teniendo como fecha límite el último día del mes de marzo de 1368 (Díaz Martín, 1997, p. 263).

En estas dos ocasiones anteriormente mencionadas, Pedro I está defendiendo más las actividades económicas y comerciales de los hebreos que a ellos mismos como comunidad, motivado esencialmente por la repercusión económica que estas actividades tenían en la corona, sin embargo, Pedro I también mostró su faceta más humana hacia el pueblo sefardí. En octubre de 1355, como veremos más adelante las tropas del Conde don Enrique de Trastámara, saquearon la judería de Toledo. Tras la liberación de la ciudad, el rey don Pedro concede el perdón real a todos los ciudadanos, con la excepción de aquellos que habían dañado la Aljama. En palabras del propio rey3 no entraron en ese perdón los "que fisieron algunos maleficios contra los mios judíos de la mi judería de Toledo" (Díaz Martín, 1997, p. 274).

\section{El círculo sefardí en torno a Pedro I de Castilla}

Son claras las medidas políticas con las que Pedro I favoreció al pueblo sefardí, pero, además, el monarca castellano, comenzó a rodearse de muchos judíos que ocuparon puestos importantes en el ámbito de las finanzas regias, así como en las de los "ricos hombres" (Valdeón, 2000a, p. 59). El 8 de noviembre de 13514 Pedro I nombra almojarifes del reino de Murcia a Mayr Avencuriel, Yuçaf Avencuriel, Çuleiman Avencuriel, Hayn Avencuriel y a Yuçaf Axages (Díaz Martín, 1997, p. 284). También llamativo es el caso del médico y astrónomo Aben Zarzel quien abandonó el reino de 
Granada, en donde vivía, para trasladarse a la corte de Castilla (Valdeón, 2000a, p. 59). A su vez el rabino de Carrión, Sem Tob, dedicó sus proverbios Morales al monarca castellano. Sem Tob comenzó su obra con las palabras "Señor noble, rrey alto", que van dirigidas a Pedro I, del que esperaba que completase y mejorase la labor llevada a cabo por su padre, el monarca Alfonso XI (Valdeón, 2000a, p. 59). Sin embargo, el representante judío de más relevancia en la corte de Pedro I fue Samuel HaLevi [1].

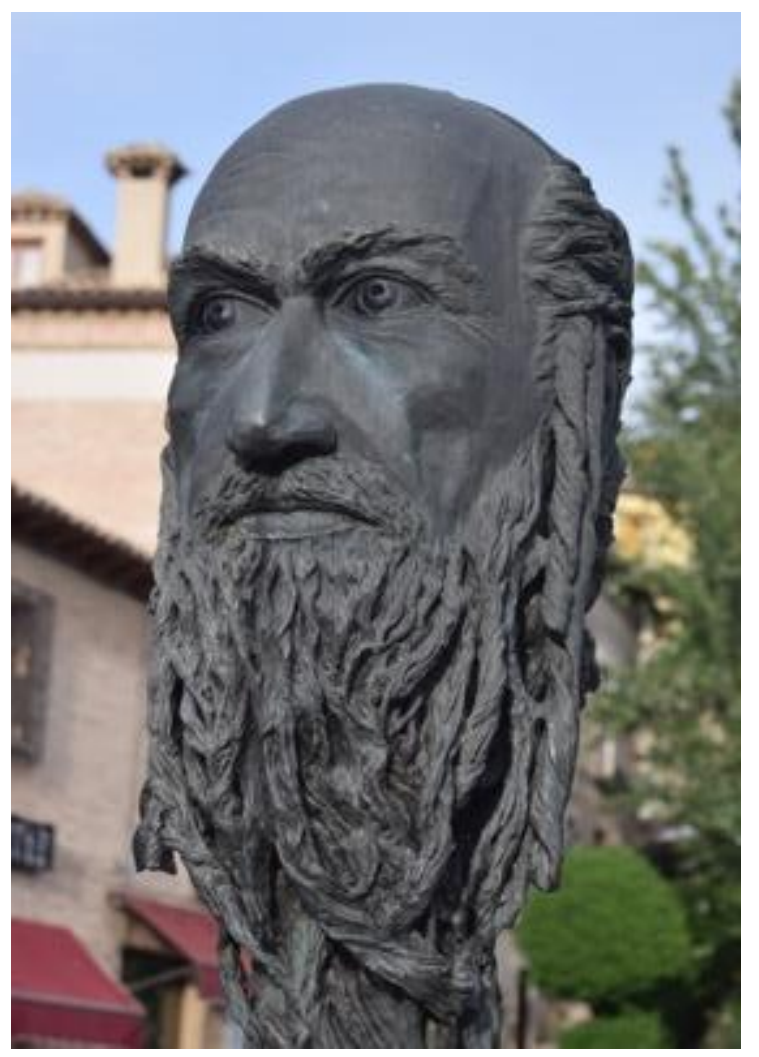

1. Estatua actual de Samuel Ha-Levi en la ciudad de Toledo. (Fotografía del autor).

Samuel Ha-Levi, actuó desde el año 1353 como Tesorero Mayor del Rey (Amrán, 2009, p. 54). El monarca, necesitado de un programa político autoritario que impusiera su figura frente a los estamentos nobiliarios, vio en la figura de Levi, un arma para llevar a cabo sus expropiaciones. Samuel Leví solicitó al monarca dos castillos donde acumuló los bienes confiscados a los nobles que se rebelaron contra el rey legítimo, consiguiendo con ello recaudar grandes riquezas y posesiones (Amrán, 2009, p. 54). Prueba de ello es un documento fechado el 5 de septiembre de 13535 por el cual, Pedro I ordenaba al adelantado mayor de Castilla, Fernán Pérez de Portocarreño y a los alcaldes y 
merinos de las merindades de Sahagún, Carrión y Cea, entregar a su tesorero mayor, Samuel Leví, los bienes de Juan Estévanez de Castellanos, que habían sido confiscados por la Corona, por haberle declarado el rey traidor (Díaz Martín, 1997, p. 181).

Podemos afirmar que además de tesorero mayor, Samuel Levi fue el prestamista principal de la corona. El judío siempre se mostró dispuesto a financiar las numerosas campañas militares y políticas del rey Pedro I. Ya afirmaba Vera y Figueroa, Conde de la Roca en 1647, como tras el nacimiento de su hija Beatriz en 1355 "Levi, su tesorero, le ofreció socorrerle con lo necesario para las ocasiones presentes" (Vera y Figueroa, 1647, p. 34). También Ferrer del Rio en 1851 comentaba como “desempeñaba Don Samuel su cargo muy á satisfacción del monarca: sin tasa le ofrecía recursos para mover sus huestes, armar flotas, guardar riquezas y mantener á la Padilla con el esplendor de soberana." (Ferrer del Rio, 1851, p. 115).

Samuel Ha-Leví, pese a ocupar uno de los cargos fundamentales del gobierno castellano, terminó cayendo en el descrédito del rey. Acusado de corrupción y robo del tesoro, el judío vio precipitada al vacío su carrera y sus bienes para finalmente perder la vida bajo tortura en las Atarazanas de Sevilla. Como afirma de nuevo Vera y Figueroa: "No le valió a Don Samuel Levi el arbitrio que años antes dio al Rey para juntar tesoros, para librar el suyo y así fue preso y otros de su casta, de quien recogió de Samuel Levi, 170 doblas, 4 marcos de plata, 20 cofres de recámara de gran precio y 80 moros, y de sus parientes 300 doblas. Y para ver si tenía más escondido fue atormentado y últimamente muerto" (Vera y Figueroa, 1647, p. 57).

\section{El asalto a las juderías de Toledo de 1355}

El pro-semitismo tan manifestado por Pedro I se convirtió en una de las armas de batalla de sus opositores (Mitre, 1994), y más en concreto de su líder, su hermanastro el conde Enrique de Trastámara. Durante el reinado de Pedro I, el Trastámara adoptó una postura antisemita mediante la cual se ganó el favor de muchas facciones populares. Veía en ello un buen camino para apartar a la masa popular cristiana del fervor al rey legítimo (Valdeón, 2000b). Desde el bando enriquista se acusó a Pedro I de ser el defensor de los herejes y los infieles. En una carta enviada el 1 de abril de 1366, Enrique II (1366-1379), ya coronado como monarca, escribe: "Aquel tirano malo enemigo de Dios (está) acrecentando e enrrequeciendo los moros e los judíos e enseñoreándolos” (Valdeón, 2000a, p. 61). 
Sin embargo, este fomento del antisemitismo por parte de Enrique de Trastámara no solo se quedó en la infamia y la propaganda, sino que se tradujo también en numerosas acciones armadas contra el pueblo sefardí. En concreto, por su interés para el estudio de la sinagoga del Tránsito, nos vamos detener en la ocurrida el mes de mayo del año 1355, en plena revuelta nobiliaria de la Liga de Toro. Don Enrique entró en la ciudad de Toledo con la intención de tomar el Alcázar, pero el conde logró convencer a algunos notables toledanos para asaltar las juderías de la ciudad (Amrán, 2009, p. 52). Sin embargo, no pudieron acceder a la judería mayor, que estaba defendida por semitas y nobles fieles al rey Pedro. Pero López de Ayala nos narra el acontecimiento del siguiente modo (López de Ayala, 1877, p. 184):

"E el Conde e el Maestre, desque entraron en la cibdad asosegaron en sus posadas; pero las sus compañas comenzaron a robar una judería apartada que dicen el Alcaná, e robáronla e mataron los judíos que fallaron fasta mil e docientas personas, omes e mujeres, grandes e pequeños. Pero la judería mayor non la pudieron tomar, que estaba cerda, e avía mucha gente dentro; e algunos caballeros que tenían ya la partida del Rey ayudaban a los judíos, e todos en uno defendían la judería mayor".

El ataque de las tropas del conde Enrique en 1355 supuso un antes y un después para la comunidad sefardí de Toledo. Como apuntó José Luís Lacave el nivel máximo de población de las juderías toledanas se alcanzó en 1350, sin embargo, ya a finales del siglo XIV se dice de algún espacio de la ciudad de Toledo “que fue judería en el pasado" (Lacave, 1992, p. 297), lo que sin duda simboliza un descenso cuantitativo de la población.

\section{La sinagoga del tránsito como testimonio político}

La Sinagoga del Tránsito de Toledo representa el mejor testimonio material de las relaciones políticosociales de Pedro I de Castilla y el pueblo hebreo. Más en concreto las relaciones entre el monarca y la comunidad sefardí toledana, con Samuel Leví a la cabeza. Como vamos a ver, este edificio se traduce como un reflejo de las ambiciones políticas de Pedro I y su tesorero mayor, pero también como una huella de las acciones que tuvieron lugar en torno a 1355.

Esta sinagoga fue levantada por Samuel Leví entre los años 1357 y 1358. Lo primero que llama la atención al abordar su estudio es que el Papa Alejando III (1159-1181), dos siglos antes, había impuesto una bula que impedía conceder licencia de construcción de nuevas sinagogas, y sin embargo Samuel Leví consiguió el permiso del rey (Torralba, 1967, p. 71). Este hecho rodea el edificio de cierto carisma excepcional. Se puede especular que la licencia fue concedida por dos razones, o bien como afirma Basilio Pavón Maldonado la obra fue levantada como una reedificación de una sinagoga 
anterior, para lo que si sería concesible licencia (Pavón Maldonado, 1976, p.141), o bien se puede plantear que la licencia de construcción fuera dada por el rey don Pedro a modo de compensación por la masacre que las tropas de Enrique de Trastámara realizaron en las juderías de Toledo en el mes de mayo de 1355 (Torralba, 1967, p. 71).

A nivel arquitectónico la sinagoga es un templo de planta rectangular, con tejado a cuatro vertientes y muros de mampostería sin prácticamente ornamento exterior. El interior sin embargo cuenta con una profusa decoración de estilo nazarí que se puede equiparar a las construcciones de Pedro I en Sevilla, Tordesillas y Astudillo. Como afirmaba Lambert parece "la gran sala de un palacio" (Cantera, 1955, p. 79). Hasta el siglo XVIII su puerta de acceso se hallaba coronada por una viga grafiada con una inscripción hebrea en la que rezaba el versículo 20 del salmo 118: "Ésta es la puerta del Señor; los justos entrarán por ella" (Lacave, 1992, p. 303). El interior de la sinagoga consiste en una única nave rectangular de 23 metros de largo por 9,50 metros de ancho y 17 metros de altura. El espacio está cubierto por una gran armadura artesonada y los muros culminados por un friso de decoración vegetal en el que se insertan arcos polilobulados con vanos ciegos y abiertos en alternancia (Palomero, 2007) [2].

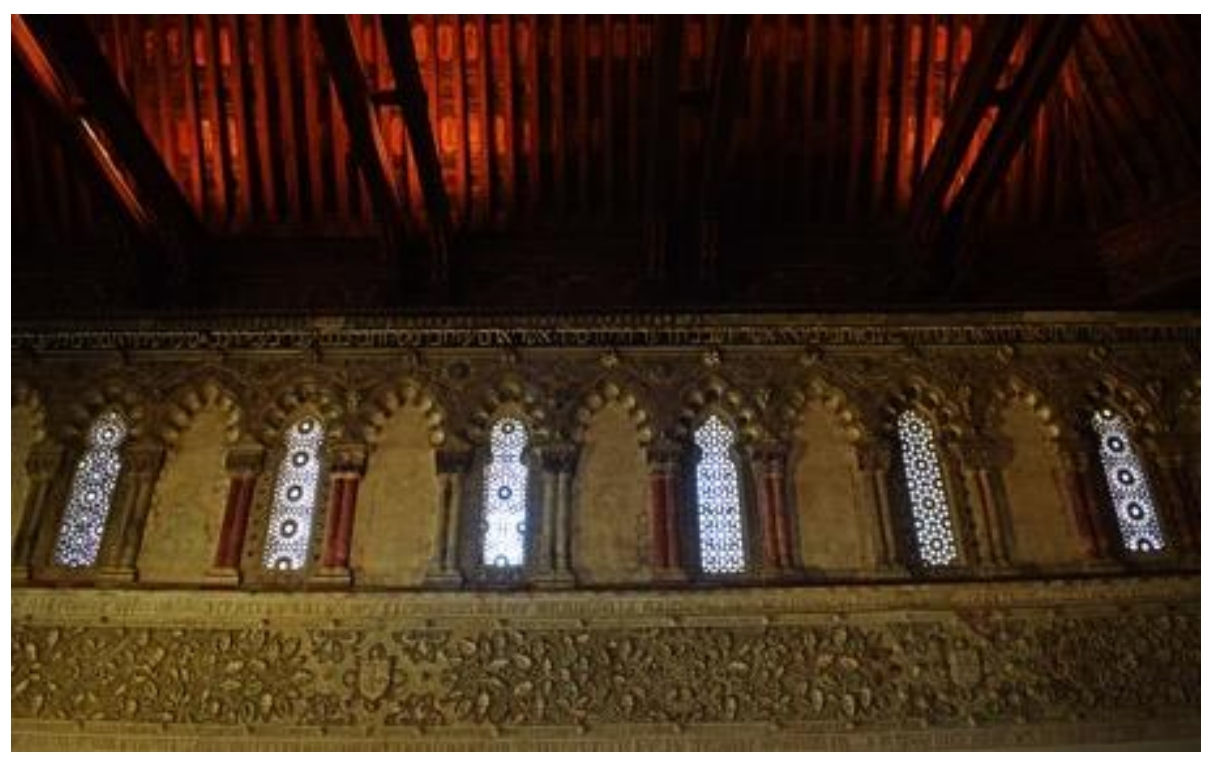

2. Detalle del friso de decoración vegetal y alternancia de vanos que recorre los muros de la Sinagoga del Tránsito. (Fotografía del autor)

La parte más destacable del templo es el muro oriental donde se encuentra el hejal para guardar los royos sagrados de la Torá. Se trata de un colosal panel de paños de sebka entrelazados levantados sobre tres arquillos polilobulados de clara influencia almohade [3]. Las yeserías están policromadas en tonos rojos verdes, azules, blancos y negros (López y Palomero, 1992, p. 211). En este panel del 
muro oriental encontramos una inscripción hebrea de suma significancia. Se trata de una alabanza al rey don Pedro enmarcada bajo el escudo de Castilla y León que reza: "El gran monarca, nuestro señor y nuestro dueño, el rey don Pedro; ¡ Sea Dios en su ayuda y acreciente su fuerza y su gloria y guárdela cual un pastor de su rebaño!" (Valdeón, 2000a, p. 59) [4]. No es la única inscripción engrandeciendo al rey, otra de ellas exhibe: "Ha hallado gracia y misericordia a los ojos de la magna águila de enormes alas, hombre de guerra, grande es su nombre entre las naciones, el monarca nuestro señor, y nuestro dueño el rey don Pedro I” (López y Palomero, 1992, p. 210). Pedro I además no es el único en disponer una epigrafía con un mensaje grandilocuente, el propio magnate y mecenas del templo, Samuel Leví, es alabado del siguiente modo en otra inscripción: "Columna diestra sobre la cual estriban la casa de Leví y la casa de Israel, ¿quién podrá decir y quién logrará agotar la loa? Diadema de imperio, joya de la majestad que se yergue en la cima de la categoría; príncipe de los príncipes del levirato, rabi Samuel Haleví” (López y Palomero, 1992, p. 210).

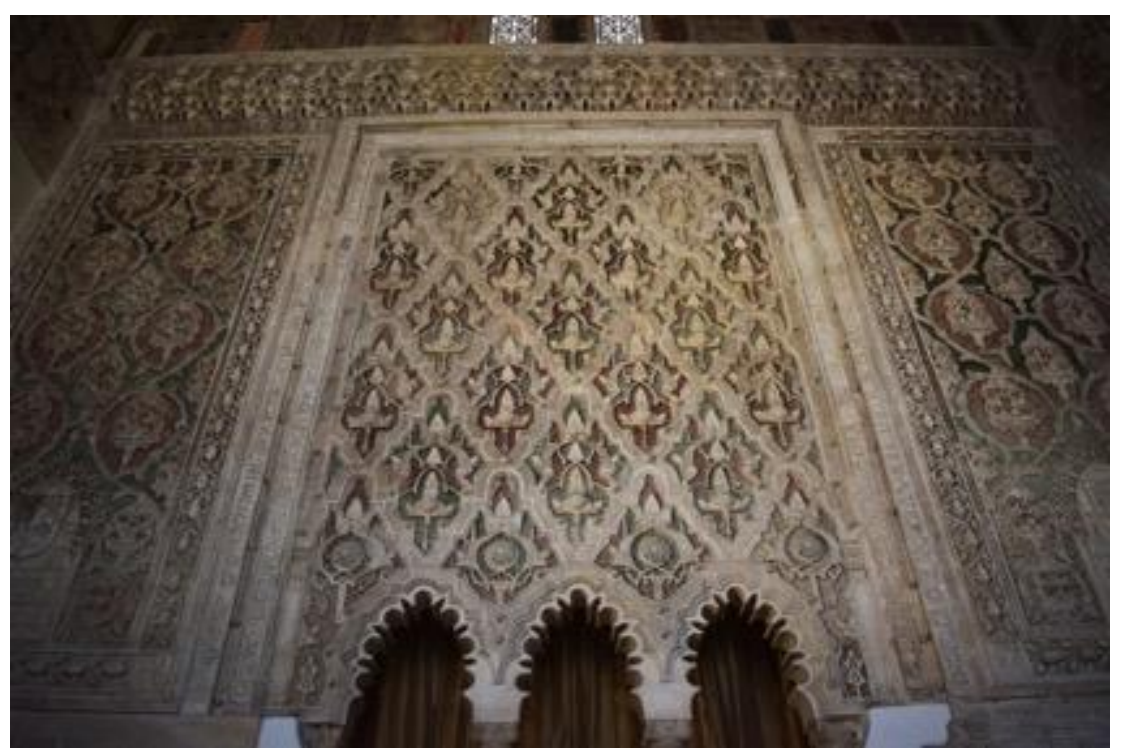

3. Muro oriental de la sinagoga donde se encuentra el hejal para guardar los royos sagrados de la Torá. (Fotografía del autor) 


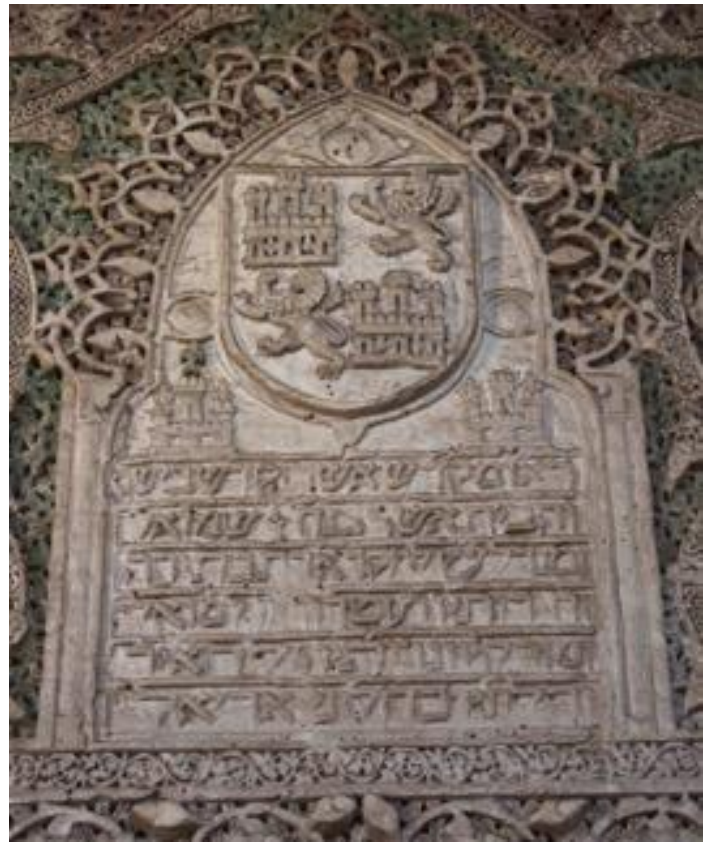

4. Detalle de la epigrafía en alabanza al rey don Pedro situada en el muro oriental de la Sinagoga del Tránsito. (Fotografía del autor)

Mediante la observación de esta epigrafía y la grandilocuencia de su lenguaje arquitectónico, se puede concluir que la sinagoga se levantó como un alarde político tanto de Samuel Leví, como del propio monarca, quienes se presentaron como grandes benefactores de la comunidad hebrea de Toledo en particular y colateralmente de todo Castilla, especialmente tras los acontecimientos de 1355. El edificio por tanto es la representación material máxima de la relación entre la corona y los judíos de Castilla.

\section{Referencias bibliográficas}

AMRÁN, Rica (2009). Judíos y conversos en el reino de Castilla, Propaganda y mensajes políticos, sociales y religiosos (siglos XIV-XVI). Junta de Castilla y León, Consejería de Cultura y Turismo: Valladolid.

CANTERA BURGOS, Francisco (1955). Sinagogas Españolas, con especial estudio de la de Córdoba y la Toledana de El Tránsito. Instituto "Arias Montano": Madrid.

DÍAZ MARTÍN, Luis Vicente (1997). Colección Documental de Pedro I de Castilla 1350-1369, vols. 1, 2, 3 y 4. Junta de Castilla y León, Consejería de Educación y Cultura: Valladolid.

FERRER DEL RIO, Antonio (1851). Examen histórico-crítico del reinado de don Pedro de Castilla. Obra premiada por voto unánime de la Real Academia Española en el certamen que abrió la misma 
en 3 de marzo de 1850. C. Monier, editor, Librero de Cámara de SS.MM. y del ministerio de Instrucción pública: Madrid.

LACAVE, José Luís (1992). Juderías y Sinagogas Españolas. Colección Sefarad, Editorial Mapfre S.A.: Madrid.

LADERO QUESADA, Miguel Ángel (1991). "Algunas reflexiones sobre los orígenes del "Estado Moderno" en Europa, (siglos XIII - XVIII)", en: GONZÁLEZ JIMÉNEZ, Manuel, (Ed.) III Jornadas Hispano-Portuguesas de Historia Medieval, La península Ibérica en la Era de los Descubrimientos, (1391-1492). Junta de Andalucía, Consejería de Cultura: Sevilla.

LÓPEZ ÁLVAREZ, Ana María, PALOMERO, Santiago (1992). “Las sinagogas españolas en sus restos arqueológicos", en: ROMERO, Elena (dir.), La vida judía en Sefarad, catálogo de la exposición celebrada en la sinagoga del Tránsito, Toledo entre noviembre de 1991 y enero de 1992. Toledo. Ministerio de Cultura, Dirección General de Bellas Artes y Archivos, Centro Nacional de Exposiciones.

LOPEZ DE AYALA, Pero (1877). "Crónica del rey don Pedro I con las enmiendas del Secretario Gerónimo Zurita y las correcciones y notas añadidas por Don Eugenio de Llaguno y Amirola, caballero de la Orden de Santiago, de la real academia de la Historia”, en: ROSELL, Cayetano (Ed.) Crónicas de los reyes de Castilla desde don Alfonso el sabio, hasta los católicos don Fernando y doña Isabel. Tomo I, Biblioteca de Autores Españoles desde la formación del lenguaje hasta nuestros días. M. Rivadeneyra editor: Madrid.

MITRE FERNANDEZ, Emilio (1994). Los judios de Castilla en tiempo de Enrique III. El pogrom de 1391. Secretariado de Publicaciones, Universidad de Valladolid: Valladolid.

PALOMERO PLAZA, Santiago (2007) "Historia de la Sinagoga de Samuel Ha-Leví y del Museo Sefardí de Toledo". Ministerio de Cultura: Toledo.

PAVÓN MALDONADO, Basilio (1976). “Un problema arqueológico en la sinagoga de El Tránsito”. Sefarad, n³6, pp. 141-144.

RUCQUOI, A. et.al. (1987). Génesis Medieval del Estado Moderno: Castilla y Navarra (1250-1370). Ámbito Ediciones S.A.: Valladolid.

SUAREZ FERNÁNDEZ, Luís (1980). Judíos Españoles en la Edad Media. Rialp: Madrid.

TORRALBA BERNALDO DE QUIROS, Felipe (1967). Los judios españoles, Rivadeneira: Madrid.

VALDEÓN BARUQUE, Julio (1966). Enrique II de Castilla: La guerra civil y la consolidación del régimen (1366-1371). Universidad de Valladolid, Secretariado de Publicaciones, Estudios y Documentos: Valladolid.

VALDEÓN BARUQUE, Julio (2000a). Judios y Conversos en la Castilla Medieval. Serie Histórica 1, Colección "Acceso al Saber", Secretariado de Publicaciones e Intercambio Editorial, Universidad de Valladolid: Valladolid.

VALDEÓN BARUQUE, Julio (2000b) El chivo expiatorio, judios, revueltas y vida cotidiana en la Edad Media. Ámbito alarife: Valladolid. 
VERA Y FIGUEROA, Juan Antonio de (1647). El Rey Don Pedro defendido. Ofrecido a la Majestad del Rey Don Felipe IV, Francisco García, Impresor del reino: Madrid. 